\title{
ANALISIS INDEKS VEGETASI MENGGUNAKAN CITRA ALOS AVNIR-2 UNTUK ESTIMASI KEBUTUHAN RUANG TERBUKA HIJAU BERDASARKAN KEBUTUHAN OKSIGEN DI KOTA DENPASAR, PROVINSI BALI
}

\author{
I Ketut Putrajaya
}

E-mail: putraketut13@gmail.com

\begin{abstract}
Abstrak: Penelitian ini bertujuan untuk: (1) mengkaji kemampuan Citra ALOS AVNIR-2 dalam mengekstraksi kerapatan vegetasi yang digunakan untuk pemetaan RTH dalam rangka estimasi ketersediaan oksigen; (2) menentukan kebutuhan RTH berdasarkan kebutuhan oksigen. Analisis regresi linier digunakan untuk mengetahui hubungan antara indeks vegetasi dengan kerapatan vegetasi sebagai pertimbangan dalam menentukan ketersediaan RTH. Kebutuhan oksigen dihitung menggunakan Metode Gerrarkis dengan mempertimbangkan variabel jumlah penduduk, kendaraan bermotor dan industri. Hasil penelitian menunjukkan bahwa transformasi NDVI menghasilkan nilai korelasi (R2) lebih baik yaitu sebesar 0,8371 dibandingkan SAVI sebesar 0,8368. Hasil uji akurasi pemetaan kerapatan vegetasi menunjukkan tingkat ketelitian sebesar 85\% dan diperoleh luasan RTH mencapai $4.872,34$ Ha atau sebesar 38,92\%. Khusus untuk RTH vegetasi tegakan dengan luas 1.868,35 Ha sehingga estimasi ketersediaan oksigen mencapai 945.852,19 kg/hari sedangkan kebutuhan oksigen penduduk, kendaraan bermotor, dan industri adalah $1.442 .680,62 \mathrm{~kg} / \mathrm{hari}$. Kebutuhan oksigen tersebut agar terpenuhi, dibutuhkan RTH dengan luas 2.894,71 Ha sehingga diperlukan penambahan RTH sebesar 981,36 Ha.
\end{abstract}

Kata Kunci: Indeks Vegetasi, Citra ALOS AVNIR-2, Kebutuhan RTH

\section{PENDAHULUAN}

Perkembangan pariwisata Kota Denpasar telah memicu perkembangan jumlah penduduk yang disertai sarana dan prasarana fisik, seperti permukiman, transportasi, industri dan sebagainya. Jumlah penduduk Kota Denpasar tahun 2013 sebanyak 846.200 jiwa, dengan laju pertumbuhan sebesar 3,72\% dan kepadatan penduduk mencapai $6.622 \mathrm{jiwa} / \mathrm{km}^{2}$ (BPS Provinsi Bali, 2014). Kebutuhan ruang dan lahan untuk menampung penduduk dan aktivitasnya yang terus meningkat, menyebabkan keberadaan RTH (Ruang
Terbuka Hijau) cenderung mengalami konversi guna lahan menjadi kawasan terbangun. Peningkatan kebutuhan lahan tersebut dapat ditinjau dari dua fenomena utama di daerah perkotaan, yaitu ekspansi daerah terbangun pada daerah non terbangun dan terjadinya densifikasi bangunan pada daerah terbangun (Suharyadi, 2011).

Berdasarkan UU RI No. 26 Tahun 2007, RTH adalah area memanjang/ jalur dan/ atau mengelompok, yang penggunaanya lebih bersifat terbuka, 
I Ketut Putrajaya. Analisis Indeks Vegetasi Menggunakan Citra Alos Avnir-2 untuk Estimasi Kebutuhan Ruang terbuka Hijau Berdasarkan Kebutuhan Oksigen Di Kota Denpasar, Provinsi Bali

tempat tumbuh tanaman, baik yang tumbuh secara alamiah maupun yang sengaja ditanam. Proporsi 30\% dinyatakan sebagai ukuran minimal untuk menjamin keseimbangan ekosistem. Penyediaan RTH dapat dikembangkan dari masalahmasalah lingkungan seperti kebutuhan oksigen. Pengembangan RTH memerlukan perencanaan dan pengelolaan yang baik agar fungsi-fungsi RTH dapat terwujud secara optimal.

Ketersediaan Citra ALOS AVNIR-2 dengan resolusi spasial $10 \mathrm{~m}$ telah membuka peluang untuk memperoleh informasi tutupan hijau yang diperlukan dalam kajian RTH. Citra ALOS AVNIR-2 belum banyak digunakan oleh pemerintah di tingkat kabupaten/ kota dan atau perusahaan swasta nasional untuk memetakan sumberdaya alam. Seperti yang dikemukakan oleh As-Syakur (2010) bahwa nilai indeks vegetasi dari Citra ALOS AVNIR-2 mempunyai hubungan dengan persentase tutupan vegetasi dimana nilai indeks vegetasi dari NDVI dan SAVI mempunyai koefisien determinasi yang paling tinggi. Sedangakan Sutanto (2012) berpendapat terkait skala pemetaan harus sesuai dengan tingkat daerah yang dipetakan, untuk daerah kota/ kabupaten citra dengan resolusi spasial $10 \mathrm{~m}$ (Citra ALOS AVNIR-2) dapat digunakan dengan skala pemetaan 1:50.000 - 1:100.000. Pemanfaatan teknologi penginderaan jauh sangat membantu agar perencanaan pembangunan RTH dapat dilakukan dengan lebih mudah, seperti dalam penelitian ini untuk analisis spasial terutama dalam penentuan kebutuhan RTH berdasarkan kebutuhan oksigen.
Berdasarkan uraian di atas, maka tujuan utama penelitian ini, yaitu untuk mengkaji kemampuan Citra ALOS AVNIR-2 dalam mengekstraksi kerapatan yang digunakan untuk pemetaan RTH dalam rangka estimasi ketersediaan oksigen. Kemudian menentukan kebutuhan RTH berdasarkan kebutuhan oksigen.

\section{METODE PENELITIAN}

\section{Lokasi Penelitian}

Penelitian ini dilakukan di Kota Denpasar, Provinsi Bali yang terletak pada koordinat $08^{\circ} 35^{\prime} 31^{\prime \prime} \mathrm{LS}-08^{\circ} 44^{\prime} 49^{\prime \prime}$ LS dan $115^{\circ} 10^{\prime} 23^{\prime \prime}$ BT - 115 16' 27" BT. Penelitian ini menjadi penting dilakukan di Kota Denpasar, mengingat kegiatan di sektor pariwisata dan sektor-sektor ikutannya mengalami perkembangan yang signifikan. Selain dampak positif, perkembangan tersebut juga menimbulkan dampak negatif seperti alih fungsi lahan bervegetasi menjadi lahan terbangun, disatu sisi masyarakat setempat memerlukan tingkat kenyamanan yang lebih baik terutama peningkatan fungsi RTH. Berdasarkan kondisi tersebut, kebutuhan RTH berdasarkan kebutuhan oksigen oleh penduduk, kendaraan bermotor, dan industri menjadi suatu kajian yang relevan dilakukan di Kota Denpasar.

\section{Bahan dan Alat Penelitian}

Data yang digunakan adalah Citra ALOS AVNIR-2 untuk ekstraksi kerapatan vegetasi. Citra Quickbird sebagai updating informasi tutupan lahan. Peta RBI skala 1:25.000, serta didukung data 
sekunder dan hasil cek lapangan. Alat penelitian yang digunakan meliputi GPS, meteran serta didukung software ENVI 4.5 dan ArcGIS 10.1.

\section{Tahapan Penelitian}

\section{Koreksi Radiometrik dan Geometrik}

Koreksi radiometrik dilakukan dengan tiga tahap yaitu, at-sensor radiance, at-sensor reflectance dan at-surface reflectance. Koreksi geometrik menggunakan metode image to map berdasarkan Peta RBI Skala 1 : 25.000. Relokasi piksel menggunakan algoritma polinomial dengan interpolasi nilai spektral nearest neighbour.

\section{Transformasi Indeks Vegetasi}

Transformasi Indeks vegetasi dalam penelitian ini bertujuan untuk pengubahan nilai piksel citra ALOS AVNIR-2 sehingga menghasilkan citra dengan nilai piksel baru yang merepresentasikan variasi vegetasi yang selanjutnya akan dikaitkan dengan RTH. Penelititan ini menggunakan 2 indeks vegetasi yaitu NDVI (Normalized Difference Vegetation Index) dan SAVI (Soil Adjusted Vegetation Index).

$$
\begin{aligned}
& \mathrm{NDVI}=\frac{\rho_{2}-\rho_{1}}{\rho_{2}+\rho_{1}} . \\
& \text { SAVI }=\frac{\rho_{2}-\rho_{1}}{\rho_{2}+\rho_{1}+L} \times(1+L) .
\end{aligned}
$$

Keterangan:

$\rho_{1}=$ Band merah

$\rho_{2}=$ Band Infra merah dekat

$\mathrm{L}=$ Faktor Kalibrasi Tanah 0.5 (Huete dan Liu, 1994 dalam Jensen, 2000).

Hasil regresi yang mempunyai nilai korelasi terbaik digunakan sebagai per- samaan untuk menghasilkan peta kerapatan vegetasi dan diuji akurasinya.

\section{Penentuan Sampel}

Justice dan Townshend (1981) dalam McCoy (2005) mengemukakan penentuan sampel kerapatan vegetasi menggunakan unit piksel terkecil yaitu:

$\mathrm{A}=\mathrm{P}(1+2 \mathrm{~L})$.

Keterangan:

$\mathrm{A}=$ ukuran minimal sampel

$\mathrm{P}=$ ukuran piksel citra

$\mathrm{L}=$ akurasi lokasi 0,5 piksel

Perkiraan akurasi lokasi pada citra resolusi menengah $10 \mathrm{~m}$ adalah 0,5 piksel sehingga ukuran sampel di lapangan dengan data citra ALOS AVNIR-2 sebesar 20 x $20 \mathrm{~m}$, membutuhkan 4 piksel sampel kerapatan vegetasi berdasarkan persebaran nilai NDVI dan SAVI yang dikelaskan berdasarkan histogramnya. Metode yang digunakan dalam pengambilan sampel adalah metode stratified random sampling

\section{Analisis Ketersediaan RTH}

Ketersediaan RTH dianalisis berdasarkan Peta Kerapatan Vegetasi diturunkan dari hasil analisis regresi indeks vegetasi dengan kerapatan vegetasi hasil pengukuran lapangan. Semakin tinggi rentangan nilai indeks vegetasi maka kerapatan vegetasi semakin tinggi, kerapatan vegetasi juga mempengaruhi jenis RTH.

\section{Analisis Kebutuhan RTH Berdasarkan Kebutuhan Oksigen}

\section{Estimasi Ketersediaan Oksigen}

Volume oksigen dihitung dengan pendekatan Gerrarkis (1974), bahwa se- 
I Ketut Putrajaya. Analisis Indeks Vegetasi Menggunakan Citra Alos Avnir-2 untuk Estimasi Kebutuhan Ruang terbuka Hijau Berdasarkan Kebutuhan Oksigen Di Kota Denpasar, Provinsi Bali

tiap $1 \mathrm{~m}^{2} \mathrm{RTH}$ menghasilkan 54 gram berat kering dan 1 gram berat kering setara dengan produksi oksigen 0,9375 gram/hari.

\section{Estimasi Kebutuhan Oksigen}

Perhitungan kebutuhan oksigen bagi penduduk mengacu pada White, dkk, (1959) dalam Wisesa (1988), bahwa manusia mengkonsumsi $0,864 \mathrm{~kg}$ oksigen/hari:

$$
\begin{aligned}
\mathrm{Pt}= & \text { jumlah penduduk keseluruhan da- } \\
& \begin{array}{l}
\text { lam wilayah kajian x } \\
\text { oksigen manusia }
\end{array} \\
& \text { kg/hari) } \ldots \text {..................... (4) }
\end{aligned}
$$

Perhitungan kebutuhan oksigen bagi kendaraan bermotor mengacu pada pendapat Wisesa (1988) dalam Syailendra

\begin{tabular}{|c|c|c|c|c|c|}
\hline \multirow[t]{2}{*}{ No } & \multirow{2}{*}{$\begin{array}{l}\text { Kendaraan } \\
\text { Bermotor }\end{array}$} & \multirow[t]{2}{*}{ Bahan Bakar } & Kebutuhan & Kebutuhan & \multirow{2}{*}{$\begin{array}{l}\text { Kebutuhan } \mathrm{O}_{2} \\
\text { (kg/jam) }\end{array}$} \\
\hline & & & $\begin{array}{l}\text { Bahan Bakar } \\
\text { (kg/PS) }\end{array}$ & $\begin{array}{l}\text { Oksigen Tiap } \\
\text { Liter BB (kg) }\end{array}$ & \\
\hline 1 & Sepeda motor & Bensin & 0,21 & 2,77 & 0,58 \\
\hline 2 & $\begin{array}{l}\text { Mobil } \\
\text { penumpang }\end{array}$ & Bensin & 0,21 & 2,77 & 11,63 \\
\hline 3 & Mobil bus & Solar & 0,16 & 2,86 & 44,32 \\
\hline 4 & Mobil beban & Solar & 0,16 & 2,86 & 22,88 \\
\hline
\end{tabular}
(2005), seperti terlihat pada tabel berikut ini.

Tabel 1. Kebutuhan Oksigen untuk Kendaraan Bermotor

(Sumber: Wisesa, 1988 dalam Syailendra, 2005)

$\mathrm{Kt}=$ jumlah kendaraan (unit) $\mathrm{x}$ jumlah bahan bakar (liter) $\mathrm{x}$ rata-rata kebutuhan oksigen $(\mathrm{kg} / \mathrm{jam})$ x 24 jam $\times 10^{-3} \mathrm{~kg}$.

Kebutuhan oksigen bagi industri, seperti yang dikemukakan oleh Ryadi (1984) dalam Wisesa (1988), bahwa kebutuhan bahan bakar untuk mesin rata- rata sebanyak 185,759 kg/hari (beroperasi selama 8 jam) dan tiap $\mathrm{kg}$ bahan bakar motor diesel memerlukan 2,86 kg oksigen.

It $=$ jumlah industri besar $\mathrm{x}$ rata-rata kebutuhan bahan bakar $(185,759 \mathrm{~kg} / \mathrm{hari}) \mathrm{x}$ kebutuhan oksigen tiap kg bahan bakar $(2,86 \mathrm{~kg})$

\section{Kebutuhan RTH Berdasarkan Kebu- tuhan Oksigen}

Penentuan luas RTH yang dibutuhkan $\left(\mathrm{m}^{2}\right)$ berdasarkan kebutuhan oksigen dilakukan dengan metode Gerrarkis (1974) dalam Wisesa (1988) sebagai berikut:

$$
\mathrm{Lt}\left(\mathrm{m}^{2}\right)=\frac{(\mathrm{Pt}+\mathrm{Kt}+\mathrm{It})(\mathrm{gr} / \mathrm{hari})}{54 \text { (gr berat kering } / \mathrm{m}^{2} * 0,9375\left(\mathrm{gr} \mathrm{O}_{2} / \text { gr berat kering }\right)} . .(7)
$$




\section{Keterangan:}

$\mathrm{Lt}=$ luas RTH pada tahun ke-t $\left(\mathrm{m}^{2}\right)$

$\mathrm{Pt}=$ jumlah kebutuhan oksigen bagi penduduk pada tahun ke- $\mathrm{t}$

$\mathrm{Kt}=$ jumlah kebutuhan oksigen bagi kendaraan bermotor tahun ke-t

It $=$ jumlah kebutuhan oksigen bagi industri pada tahun ke-t

54 = konstanta $1 \mathrm{~m}^{2}$ luas RTH menghasilkan 54 gram berat kering tanaman per hari.

$0,9375=$ konstanta bahwa 1 gram berat kering tanaman setara produksi oksigen 0,9375

gr.

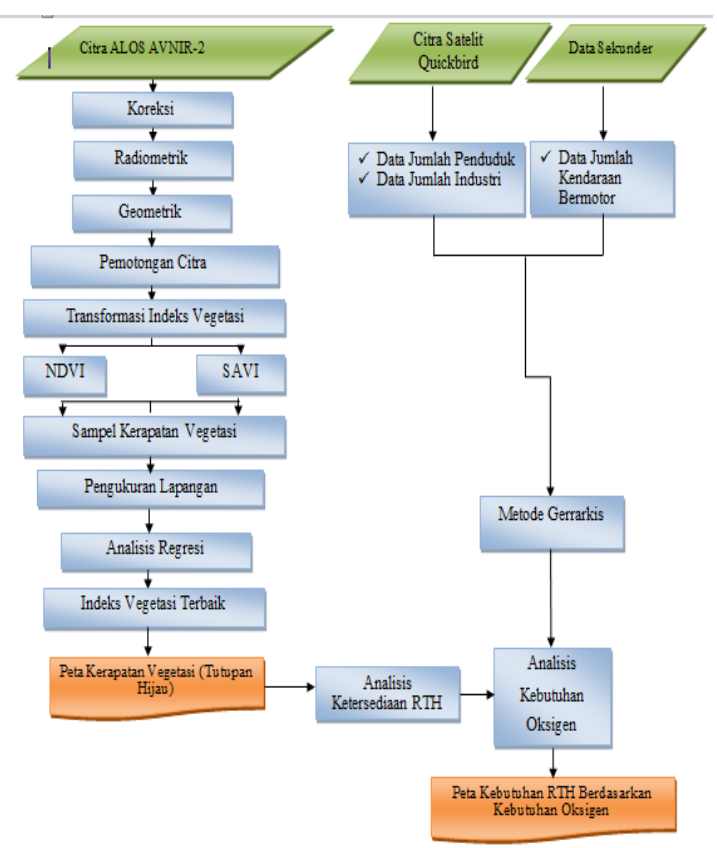

Gambar 1 Diagram Alir Penelitian

\section{HASIL DAN PEMBAHASAN}

\section{Analisis Ketersediaan RTH}

\section{Transformasi Indeks Vegetasi}

Berdasarkan proses density slice yang dilakukan, maka diperoleh perbandingan hasil transformasi NDVI dan
SAVI seperti terlihat pada Gambar 1 berikut ini. 
54

I Ketut Putrajaya. Analisis Indeks Vegetasi Menggunakan Citra Alos Avnir-2 untuk Estimasi Kebutuhan Ruang terbuka Hijau Berdasarkan Kebutuhan Oksigen Di Kota Denpasar, Provinsi Bali

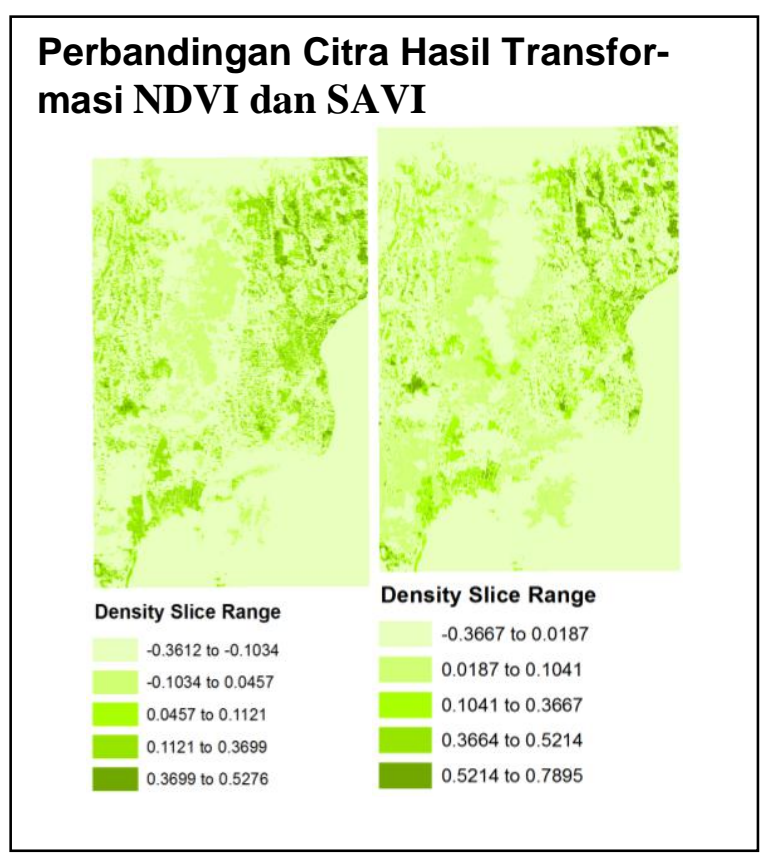

\section{Gambar 2 Citra Hasil Transformasi (a) NDVI; (b) SAVI}

(Sumber: Pengolahan Data, 2015)

Nilai kerapatan vegetasi diturunkan dari suatu model yang dibangun antara nilai indeks vegetasi dengan kerapatan vegetasi hasil pengukuran lapangan yang disebut sebagai analisis regresi linier.

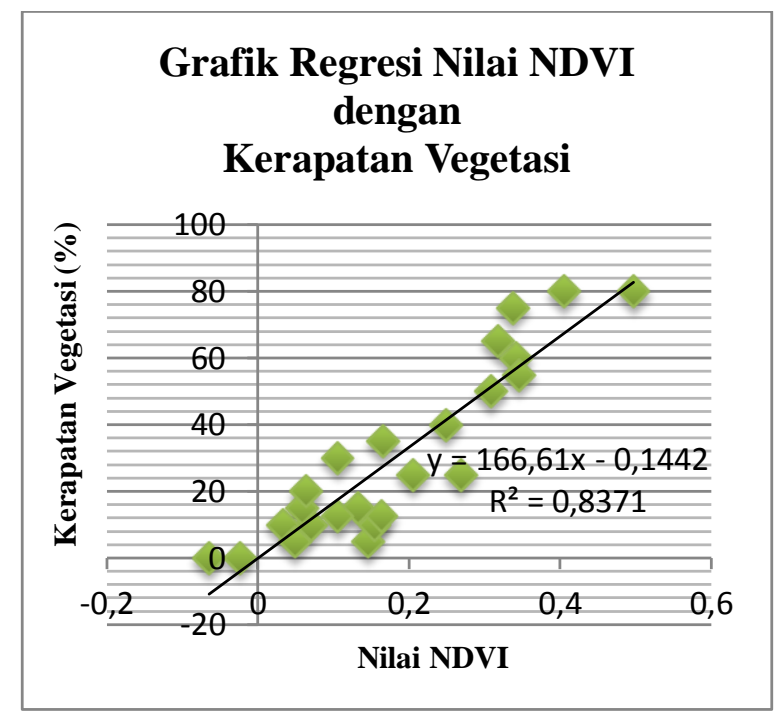

Gambar 3 Grafik regresi linier nilai NDVI dengan kerapatan vegetasi (Sumber: Pengolahan Data, 2015) 


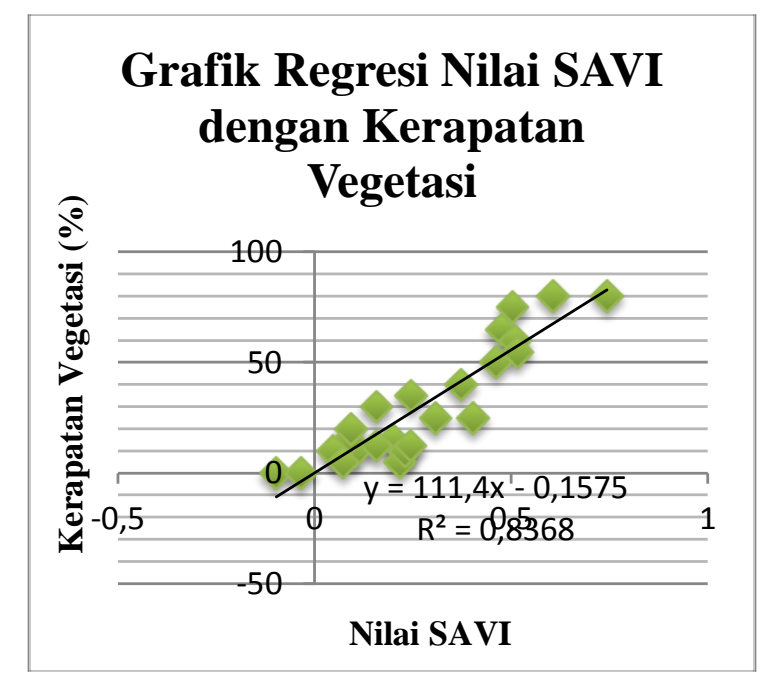

\section{Gambar 4 Grafik regresi linier nilai SAVI dengan kerapatan vegetasi} (Sumber: Pengolahan Data, 2015)

Berdasarkan analisis regresi, indeks vegetasi NDVI menghasilkan nilai korelasi dengan selisih sedikit lebih baik yaitu 0,8371 dibandingkan SAVI sebesar 0,8368 . Hal tersebut mengindikasikan bahwa baik indeks vegetasi NDVI maupun SAVI memiliki korelasi yang kuat terhadap persentase kerapatan vegetasi hasil pengukuran lapangan. Berdasarkan hasil dari model regresi linier, selanjutnya dapat diputuskan bahwa citra hasil
NDVI yang diturunkan menjadi peta kerapatan vegetasi melalui perhitungan nilai piksel pada citra NDVI menggunakan persamaan $\mathrm{y}=166,61 \mathrm{x}-0,1442$. Setelah dikoncersi dengan rumus/ persamaan di atas, maka dapat tentukan kelas kerapatan vegetasi/ peta tutupan hijau (Gambar 4) berdasarkan indeks vegetasi. Untuk lebih jelasnya mengenai persentase luasab vegetasi, dapat dilihat pada Tabel 2 berikut ini.

Tabel 2. Tutupan Hijau Berdasarkan Transformasi NDVI

\begin{tabular}{llllll}
\hline No & Nilai NDVI & $\begin{array}{l}\text { Luas } \\
(\mathrm{Ha})\end{array}$ & Persentase $(\%)$ & $\begin{array}{l}\text { Kerapatan Veg- } \\
\text { etasi }(\%)\end{array}$ & Kategori \\
\hline 1 & $\leq-0,1298$ & $7.648,01$ & 64,84 & - & Non RTH \\
2 & $-0,1298-0,0345$ & $2.279,69$ & 19,33 & $<25$ & Sangat Rendah \\
3 & $0,0346-0,1989$ & 724,30 & 6,14 & $25-50$ & Rendah \\
4 & $0,1990-0,3633$ & 974,94 & 8,26 & $51-75$ & Sedang \\
5 & $\geq 0,3634$ & 169,11 & 1,35 & $>75$ & Tinggi \\
\hline
\end{tabular}

(Sumber: Hasil Pengolahan Data, 2015)

Berdasarkan uraian di atas, ketersediaan RTH di Kota Denpasar melalui analisis kerapatan vegetasi diperoleh lua- san mencapai 4.872,34 Ha atau sebesar $38,92 \%$ dari luas Kota Denpasar. Secara spasial, sebaran masing-masing kerapatan 
56

I Ketut Putrajaya. Analisis Indeks Vegetasi Menggunakan Citra Alos Avnir-2 untuk Estimasi Kebutuhan Ruang terbuka Hijau Berdasarkan Kebutuhan Oksigen Di Kota Denpasar, Provinsi Bali

vegetasi dapat dilihat pada Peta Kerapatan Vegetasi Kota Denpasar.

Peta kerapatan vegetasi yang dihasilkan perlu diuji ketelitiannya agar informasi yang dihasilkan benar-benar merepresentasikan kondisi sebenarnya di daerah penelitian. Uji akurasi dilakukan pada 20 titik sampel yang tersebar secara merata, namun sampel yang diambil mewakili variasi kerapatan vegetasi Kota Denpasar. Berikut ini merupakan Tabel 3 untuk uji ketelitian pemetaan kerapatan vegetasi.

\section{Tabel 3. Uji Ketelitian Akurasi Pemetaan Kerapatan Vegetasi}

\begin{tabular}{|c|c|c|c|c|c|c|c|c|}
\hline Kerapatar & Veg- & & $\mathrm{ilC}$ & $\mathrm{KLa}$ & ang & & Jumlah Sam- & Sampel Benar \\
\hline & & A & B & $\mathrm{C}$ & $\mathrm{D}$ & $\mathrm{E}$ & & \\
\hline$\frac{O}{\omega} \frac{\omega}{\omega} \cdot \bar{\omega}$ & A & 2 & 1 & & & & 3 & 2 \\
\hline 흔 & B & & 3 & & & & 3 & 3 \\
\hline$\overline{\bar{\omega}} \bar{\Phi} \stackrel{\infty}{\infty}$ & $\mathrm{C}$ & & & 3 & & & 3 & 3 \\
\hline & D & & & 1 & 5 & & 6 & 5 \\
\hline & E & & & & 1 & 4 & 5 & 4 \\
\hline Jumlah & & 2 & 4 & 4 & 6 & 4 & 20 & 17 \\
\hline
\end{tabular}

(Sumber: Hasil Pengolahan Data dan Cek Lapangan, 2015)

Keterangan:

$\mathrm{A}=$ Non RTH

$\mathrm{B}=$ Kerapatan vegetasi sangat rendah

$\mathrm{C}=$ Kerapatan vegetasi rendah

$\mathrm{D}=$ Kerapatan vegetasi sedang

$\mathrm{E}=$ Kerapatan vegetasi tinggi

$$
\begin{aligned}
\text { Akurasi }(\%)= & \frac{\text { Jumlah sampel benar }}{\text { Jumlah total sampel }} \times 100 \\
& =\frac{17}{20} \times 100 \\
& =85 \%
\end{aligned}
$$

Berdasarkan transformasi NDVI dan hasil pengukuran lapangan maka diperoleh nilai indeks vegetasi yang dapat dijadikan acuan dalam penentuan jenisjenis RTH seperti terlihat pada tabel berikut ini. 
Tabel 4. Hubungan Nilai NDVI Terhadap Jenis RTH

\begin{tabular}{|c|c|c|c|c|}
\hline No & Nilai NDVI & & Kerapatan & Jenis RTH \\
\hline 1 & $\begin{array}{l}-0,1298 \\
0,0345\end{array}$ & - & $\begin{array}{l}\text { Sangat ren- } \\
\text { dah }\end{array}$ & $\begin{array}{l}\text { Taman kantor/rumah, } \\
\text { Rumput, sawah sebelum } \\
\text { tanam }\end{array}$ \\
\hline 2 & $\begin{array}{l}0,0346 \\
0,1989\end{array}$ & - & Rendah & $\begin{array}{l}\text { Pemakaman, jalur hijau } \\
\text { jalan, sawah }\end{array}$ \\
\hline 3 & $\begin{array}{l}0,1990 \\
0,3633\end{array}$ & - & Sedang & $\begin{array}{l}\text { Hutan bakau, jalur sempa- } \\
\text { dan sungai, sawah }\end{array}$ \\
\hline 4 & $\geq 0,3634$ & & Tinggi & $\begin{array}{l}\text { Hutan kota, taman kota, } \\
\text { sawah dewasa, jalur sem- } \\
\text { padan sungai }\end{array}$ \\
\hline
\end{tabular}

(Sumber: Hasil Pengolahan Data, 2015)

Jenis-jenis RTH berdasarkan nilai NDVI dan kerapatan vegetasi jika dihubungkan dengan persentase RTH pada Tabel 4 maka dapat dikelompokkan antara RTH publik dan RTH privat. RTH publik memiliki kerapatan dari rendah, sedang hingga tinggi dengan jenis RTH terdiri dari pemakaman, jalur hijau jalan, hutan bakau, jalur sempadan sungai, hutan kota dan taman kota. Persentase luasan mencapai $18,45 \%$, angka tersebut diperoleh setelah dilakukan pengurangan pada RTH jenis sawah karena pada da- sarnya sawah masih tergolong RTH privat. RTH privat memiliki tingkat kerapatan sangat rendah dengan jenis RTH meliputi Taman kantor/ rumah, Rumput, dan ditambah dengan RTH jenis sawah. Persentase luasan dari RTH privat mencapai $20,47 \%$. Jika memperhati-kan UU RI No. 26 Tahun 2007 yang merekomendasikan RTH publik 20\% dan RTH privat $10 \%$, maka kondisi RTH di Kota Denpasar masih tergolong belum seimbang. 
I Ketut Putrajaya. Analisis Indeks Vegetasi Menggunakan Citra Alos Avnir-2 untuk Estimasi Kebutuhan Ruang terbuka Hijau Berdasarkan Kebutuhan Oksigen Di Kota Denpasar, Provinsi Bali

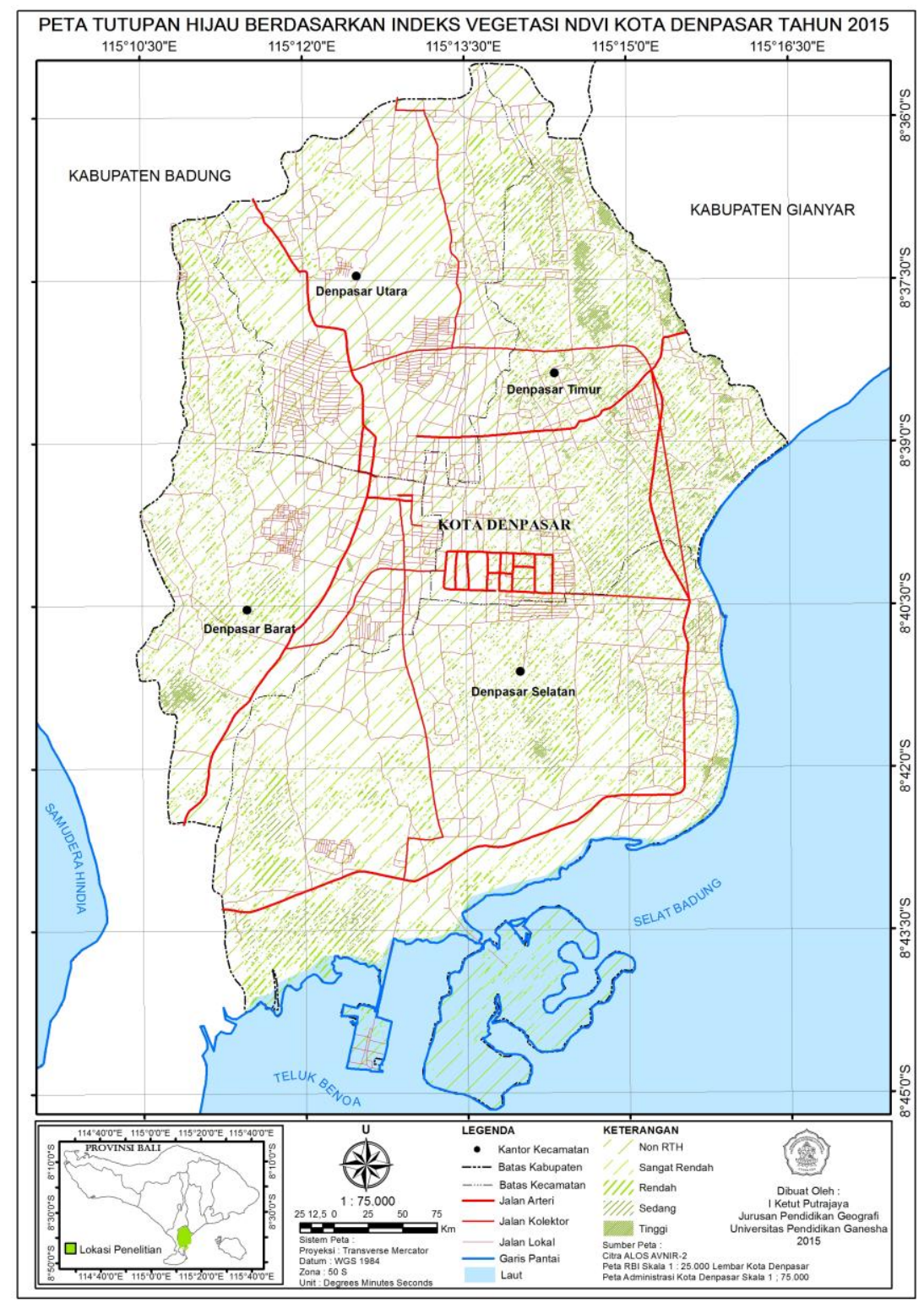

Gambar 5 Peta Tutupan Hijau Berdasarkan Nilai NDVI

Setelah mengetahui jenis-jenis RTH berdasarkan nilai NDVI dan kerapatan vegetasi, maka penting untuk dibedakan antara RTH dan non RTH. Tujuan membedakan antara RTH dan Non RTH agar dapat dibuat Peta Sebaran RTH yang selanjutnya digunakan untuk analisis pola sebaran RTH di Kota Denpasar, apakah cenderung mengelompok, menyebar atau memanjang. Memperjelas pernyataan ter- sebut, maka disajikan Peta Sebaran RTH Kota Denpasar seperti terlihat pada Peta Sebaran RTH Kota Denpasar (Gambar 5).

\section{Analisis Kebutuhan RTH Berdasarkan Kebutuhan Oksigen}

Estimasi Ketersediaan dan Kebutuhan Oksigen 
Perhitungan ketersediaan oksigen dengan metode Gerrarkis (1974) dalam Fandeli (2009), bahwa setiap $\mathrm{m}^{2} \mathrm{RTH}$ menghasilkan 54 gr berat kering dan 1 gr berat kering setara dengan produksi oksi- gen 0,9375 gram/hari. Luas RTH vegetasi tegakan adalah 1.868,35 Ha, sehingga ketersediaan oksigennya adalah 945.852,19 kg/hari.

Tabel 5. Estimasi Kebutuhan Oksigen untuk Masing-Masing Variabel

\begin{tabular}{lll}
\hline No & Variabel & Kebutuhan Oksigen $(\mathrm{kg} / \mathrm{hari})$ \\
\hline 1 & Penduduk (Manusia) & $740.082,5$ \\
2 & Kendaraan Bermotor & $585.718,5$ \\
3 & Industri & $116.879,6$ \\
\hline \multicolumn{2}{l}{ Total Kebutuhan } & $1.442 .680,62$
\end{tabular}

(Sumber: Hasil Pengolahan Data, 2015)

\section{Estimasi Kebutuhan RTH}

Kebutuhan RTH dihitung berdasarkan kebutuhan oksigen untuk masingmasing indikator menggunakan metode

$$
\begin{aligned}
\mathrm{Lt} & =\frac{(740.082,5+585.718,5+116.879,6)(\mathrm{kg} / \mathrm{hr})}{\left(54 \mathrm{gr} / \mathrm{m}^{2}\right) \times(0,9375 \mathrm{gr} / \mathrm{hr})} \\
& =2.849,71 \mathrm{Ha}
\end{aligned}
$$

Luas RTH vegetasi tegakan yang dibutuhkan adalah 2.849,71 Ha, sementara luas RTH eksisting adalah $1.868,35$ Ha. Sehingga RTH khususnya vegetasi
Gerrarkis (1974) dalam Fandeli (2009), yaitu:

tegakan sebagai penyedia oksigen masih mengalami kekurangan sebesar 981,36 Ha atau 8,32\%.

Tabel 6. Estimasi Kebutuhan RTH Berdasarkan Kebutuhan Oksigen

\begin{tabular}{llllll}
\hline No & $\begin{array}{l}\text { Konsumen } \\
\text { Oksigen }\end{array}$ & $\begin{array}{l}\text { Kebutuhan } \\
\text { Oksigen }(\mathrm{kg} / \mathrm{hr})\end{array}$ & $\begin{array}{l}\text { Estimasi RTH } \\
(\mathrm{Ha})\end{array}$ & $\begin{array}{l}\text { RTH } \\
(\mathrm{Ha})\end{array}$ & $\begin{array}{l}\text { Eksisting } \\
\text { KTH }(\mathrm{Ha})\end{array}$ \\
\hline 1 & Penduduk & $740.082,5$ & & & \\
2 & $\begin{array}{l}\text { Kendaraan } \\
\text { Bermotor }\end{array}$ & $585.718,5$ & $2.894,71$ & $1.868,35$ & 981,36 \\
3 & Industri & $116.879,6$ & & & \\
\hline
\end{tabular}

Sumber: Hasil Pengolahan Data, 2015 
56

I Ketut Putrajaya. Analisis Indeks Vegetasi Menggunakan Citra Alos Avnir-2 untuk Estimasi Kebutuhan Ruang terbuka Hijau Berdasarkan Kebutuhan Oksigen Di Kota Denpasar, Provinsi Bali

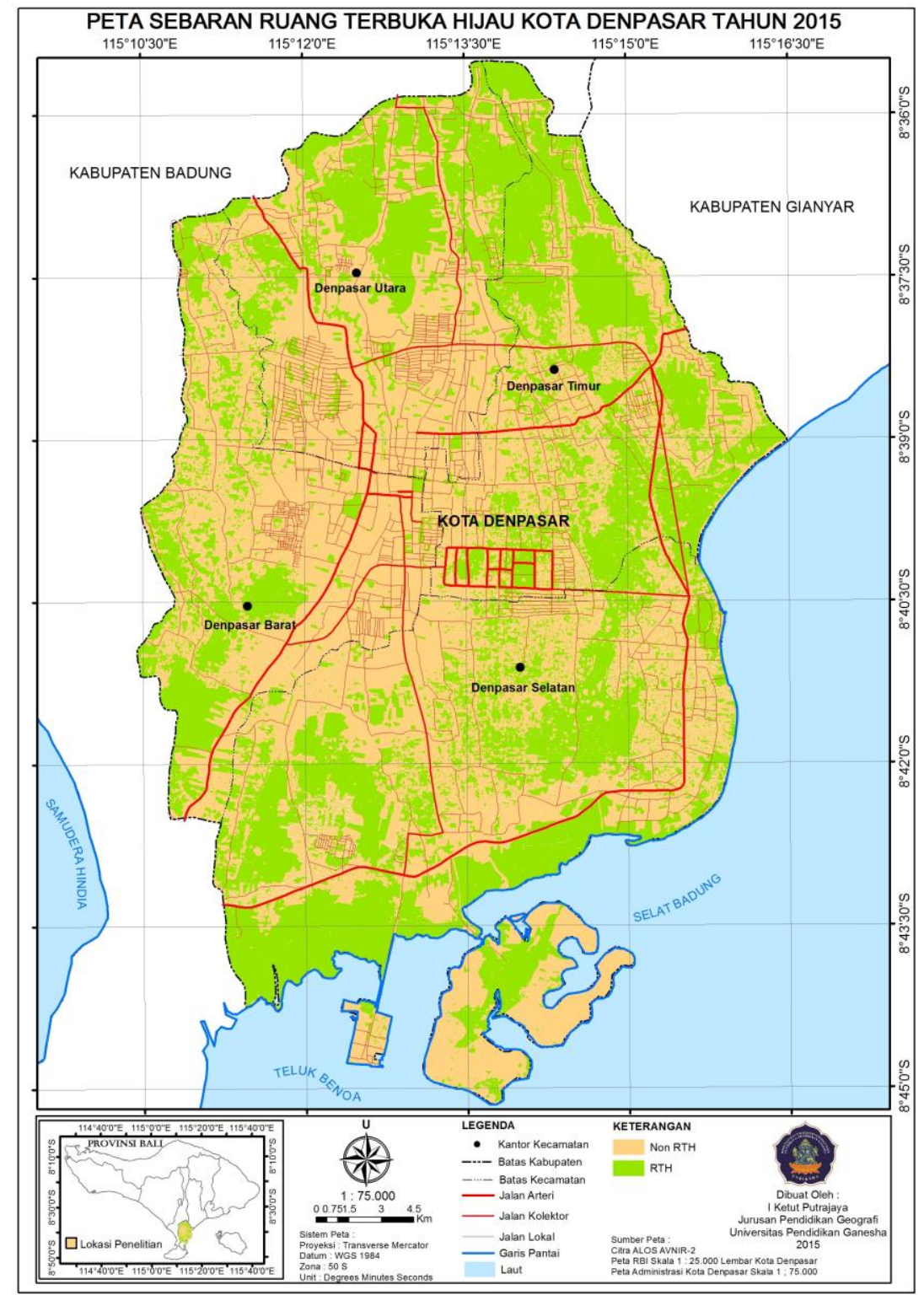

Gambar 6 Peta Sebaran Ruang Terbuka Hijau Eksisting Kota Denpasar 


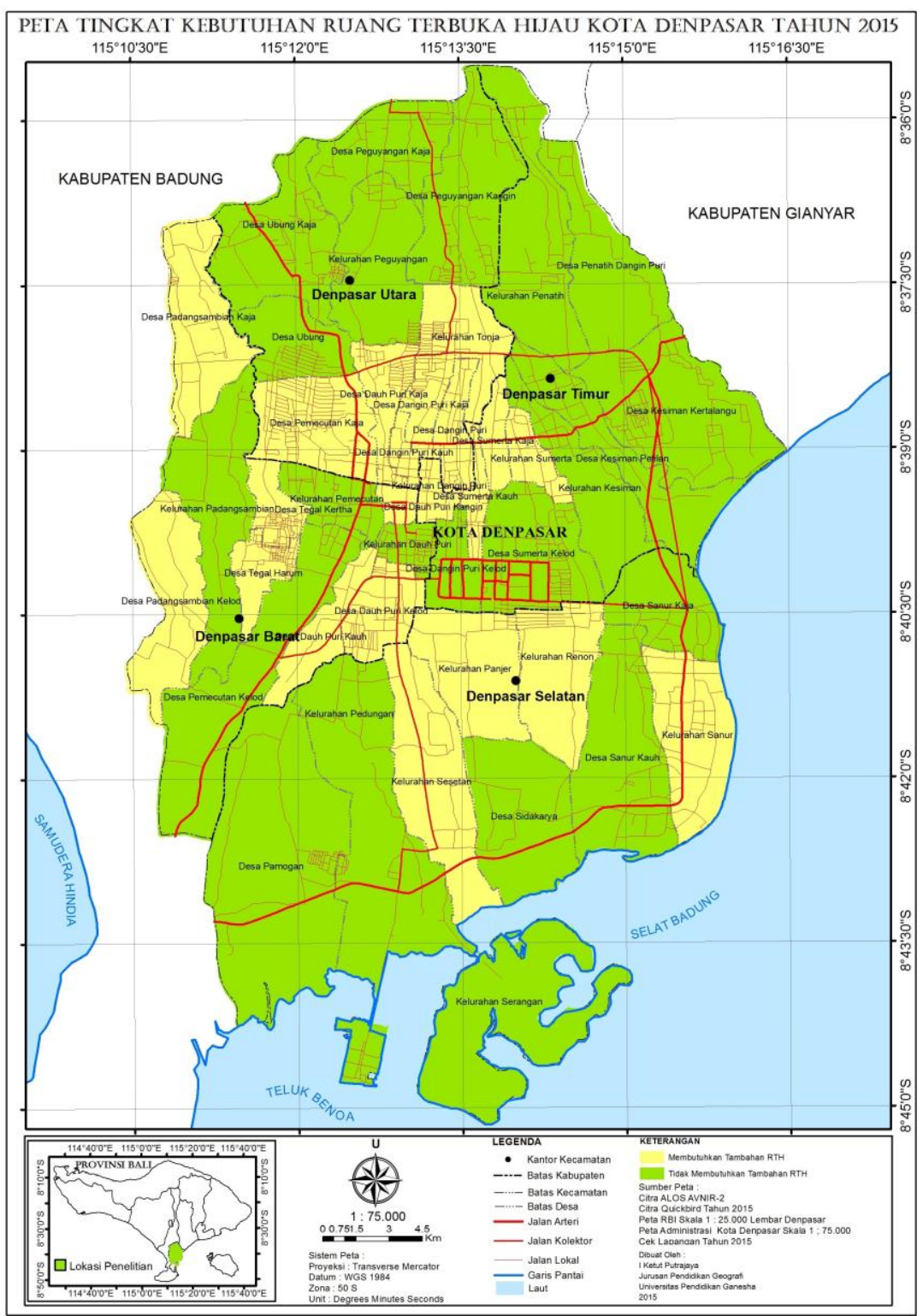

\section{Gambar 7 Peta Tingkat Kebutuhan Ruang Terbuka Hijau Kota Denpasar}

\section{KESIMPULAN}

Analisis Citra ALOS AVNIR-2 untuk mengetahui kerapatan ve-getasi melalui transformasi NDVI menghasilkan nilai korelasi $\left(\mathrm{R}^{2}\right)$ lebih baik yaitu sebesar 0,8371 dibandingkan SAVI sebesar 0,8368. Hasil uji akurasi peme-taan kerapatan vegetasi menun-jukkan tingkat ketelitian sebesar $85 \%$ dan diperoleh luasan RTH mencapai 4.872,34 Ha atau se- besar 38,92 \%, Khusus untuk RTH vegetasi tegakan dengan luas $1.868,35$ Ha.

Ketersediaan RTH kategori vegetasi tegakan adalah 1.868,35 $\mathrm{Ha}$ yang menghasilkan oksigen sebesar 945.852,19 kg/hari. Kebutuhan oksigen Beberapa kelurahan yang memerlukan tambahan RTH antara lain, Kelurahan Tonja, Desa 
I Ketut Putrajaya. Analisis Indeks Vegetasi Menggunakan Citra Alos Avnir-2 untuk Estimasi Kebutuhan Ruang terbuka Hijau Berdasarkan Kebutuhan Oksigen Di Kota Denpasar, Provinsi Bali

Dauh Puri Kaja, Dangin Puri Kaja, Pemecutan Kaja, Sumerta Kaja, Dangin Puri, Dangin Puri Kauh, Kelurahan Sumerta, Desa Sumerta Kauh, Dauh Puri Kangin, Padangsambian Kaja, Tegal Kertha, Tegal Harum, Padangsambian Kelod, Dauh Puri Kelod, Dauh Puri Kauh, Kelurahan Dangin Puri, Panjer, Sesetan, Renon dan Kelurahan Sanur. berdasarkan jumlah penduduk, kendaraan bermotor, dan industri adalah sebesar 1.442.680,62 $\mathrm{kg} /$ hari, sehingga untuk memenuhi kebutuhan oksigen tersebut dibutuhkan RTH dengan luas mencapai 2.894,71 Ha. Angka tersebut menunjukkan bahwa ketersediaan RTH belum memenuhi kebutuhan oksigen di Kota Denpasar, sehingga perlu upaya penyediaan RTH tambahan sebesar 981,36 Ha untuk menjaga keseimbangan RTH di Kota Denpasar.

\section{DAFTAR PUSTAKA}

Anderson, James R., Ernest E. Hardy, John T. Roach and Richard E. Witmer. 1976. A Land Use and Land Cover Classification Sys-tem for Use Remote Sensor Data. Washington: United Sta-tes Government Printing Office.

As-Syakur, A.R. 2011. Analisis Indeks Vegetasi Menggunakan Citra ALOS AVNIR-2 dan Sistem Informasi Geografis (SIG) untuk Evaluasi Tata Ruang Kota Denpasar. Jurnal Bumi Lestari. 9, 1-11.

Badan Pusat Statistik. 2014. Provinsi Bali dalam Angka. Bali: BPS.

Danoedoro, P. 2012. Pengantar Penginderaan Jauh Digital. Yogyakarta: C.V Andi Offset.
Fandeli, C., Muhhamad. 2009. Prin-sipPrinsip Dasar Mengkonser-vasi Lansekap. Yogyakarta: Gadjah Mada University Press.

Fandeli, C., K. Mukhlison. 2004. Perhutanan Kota. Yogyakarta: Fakultas Kehutanan Universitas Gadjah Mada.

Gasman. 1984. Peranan TumbuhTumbuhan dalam Menghasilkan Oksigen. Jakarta: Harian A.B.

Jensen, J.R. 1996. Introductory Image Processing: A Remote Sensing Perspective. New Jersey-USA: Prentice Hall.

. 2000. Remote sensing of The Environmental Earth Resource Perspective. New Jersey-USA: Prentice Hall.

Liu, Ting. 2012. Mapping Vegetation in an Urban Area with Stratified Clasification and Multiple Endmember Spectral Mixture Analysis. Remote Sensing of Environment. 133, 251264.

McCoy, R.M. 2005. Field Methods in Remote Sensing. New York: The Guildford Press.

Rashed, T. and C. Jurgens. 2010. Remote Sensing of urban and Suburban Areas. Remote Sensing and Digital Image Processing. 10, 56.

Suharyadi, R. 2011. Interpretasi Hibrida Citra Satelit Resolusi Spasial Menengah untuk Kajian Densifikasi Bangunan Daerah Perkotaan di Daerah Perkotaan Yogyakarta. Disertasi. Yogyakarta: Fakultas Geografi, Universitas Gadjah Mada.

Sutanto. 2012. Metode Penelitian Penginderaan Jauh. Yogyakarta: Ombak

Wisesa, S.P.C. 1988. Studi Pengembangan Hutan Kota di Wilayah Kotamadya Bogor. Jurusan Konserva- 
sio Sumber Daya Hutan, Fakultas Kehutanan, Institut Pertanian Bogor.

Yuan, Fei. 2007. Comparison of Impervious Surface Area and Normalized Difference Vegetation Index as Indicators of Surface Urban Heat Island Effects in Landsat Imagery. Remote Sensing of Environment. 106, 375-386.

Peraturan Pemerintah Dalam Negeri No. 1 Tahun 2007 Tentang Penataan
Ruang Terbuka Hijau Kawasan Perkotaan.

Peraturan Menteri Pekerjaan Umum No. 05/PRT/M/2008 Tentang Pedoman Penyediaan dan Pemanfaatan Ruang Terbuka Hijau di Kawasan Perkotaan.

Undang-Undang Republik Indonesia No. 26 Tahun 2007 Tentang Penataan Ruang. 